\title{
A prospective cohort study assessing clinical referral management \& workforce allocation within a UK regional medical genetics service
}

\section{This paper has been amended since online publication and a corrigendum also appears in this issue}

\author{
Caroline Benjamin ${ }^{\star 1,2}$, Catherine Houghton ${ }^{2,3}$, Claire Foo ${ }^{2}$, Chris Edgar ${ }^{2}$, Gail Mannion ${ }^{2}$, Jan Birch ${ }^{2}$, Ian Ellis ${ }^{2}$ \\ and Astrid Weber ${ }^{2}$
}

Ensuring patient access to genomic information in the face of increasing demand requires clinicians to develop innovative ways of working. This paper presents the first empirical prospective observational cohort study of UK multi-disciplinary genetic service delivery. It describes and explores collaborative working practices including the utilisation and role of clinical geneticists and non-medical genetic counsellors. Six hundred and fifty new patients referred to a regional genetics service were tracked through 850 clinical contacts until discharge. Referral decisions regarding allocation of lead health professional assigned to the case were monitored, including the use of initial clinical contact guidelines. Significant differences were found in the cases led by genetic counsellors and those led by clinical geneticists. Around a sixth, $16.8 \%(109 / 650)$ of referrals were dealt with by a letter back to the referrer or re-directed to another service provider and $14.8 \%(80 / 541)$ of the remaining patients chose not to schedule an appointment. Of the remaining 461 patients, genetic counsellors were allocated as lead health professional for $46.2 \%(213 / 461)$. A further 61 patients did not attend. Of those who did, 86.3\% (345/400) were discharged after one or two appointments. Genetic counsellors contributed to $95 \%$ (784/825) of total patient contacts. They provided $93.7 \%(395 / 432)$ of initial contacts and $26.8 \%(106 / 395)$ of patients were discharged at that point. The information from this study informed a planned service re-design. More research is needed to assess the effectiveness and efficiency of different models of collaborative multi-disciplinary working within genetics services.

European Journal of Human Genetics (2015) 23, 996-1003; doi:10.1038/ejhg.2015.33; published online 11 March 2015

\section{INTRODUCTION}

Over the last few years advances in technology have resulted in a rapid increase in the number of gene tests available. In parallel, there has been an increase in the number of referrals to genetic services due to heightened public and health professional awareness of the potential of genomic information. ${ }^{1,2}$ Recent work indicates that workforce interventions within service re-organisation; including telephone counselling by genetic counsellors, ${ }^{3}$ the provision of more genetic specialists in rural areas ${ }^{4}$ and changes to the referral management systems ${ }^{5}$ can have a significant effect on the ability of patients to access genetic services. ${ }^{6}$ A systematic literature review entitled 'Interventions to improve patient access, service utilisation and cost of providing genetic counselling services' is currently planned. ${ }^{7}$

The present study describes the usual care pathways of a UK regional genetics service in 2011-2012. The service model required all patients to be seen initially by a genetic counsellor. After this initial appointment some were discharged, while others required subsequent appointments. These were either by a genetic counsellor alone, by a joint appointment by both a clinical geneticist and a genetic counsellor, or a clinical geneticist alone. One aim of the study was to monitor the use of a revised set of initial clinical contact guidelines (ICCG) with the aim of reducing the proportion of home visits (HVs) and increasing the proportion of telephone contacts. The service provided $26 \%$ of its initial contacts by a HV in 2010-2011.

Within UK regional genetic services clinical patient contact is provided by a multi-disciplinary team - 'a team of professionals including representatives of different disciplines who coordinate the contributions of each profession, which are not considered to overlap, in order to improve patient care'. ${ }^{8}$ Disciplines represented include medical professionals (clinical geneticists), genetic counsellor professionals (genetic counsellors) and nursing professionals (registered nurses) ${ }^{9}$

A systematic review of research literature investigating the role of the non-medical genetic counsellor indicated that genetic counsellors 'undertake a significant workload associated with direct patient care and this appears to be acceptable to patients'. ${ }^{10}$ The proportion of patients seen by genetic counsellors without a medical practitioner being present ranged between 39 and 50\% and included patients with up to 79 different conditions. However, no empirical research studies of the genetic counsellor role were found from any of the European

${ }^{1}$ Health Research Methodology and Implementation Hub (HeRMI), School of Health, University of Central Lancashire (UCLan), Preston, UK; ${ }^{2}$ Merseyside and Cheshire Clinical Genetics Service, Liverpool Women's (NHS) Foundation Hospital Trust, Liverpool, UK; ${ }^{3}$ Manchester Centre for Genomic Medicine, Central Manchester University Hospitals (NHS) Foundation Trust, Manchester, UK

*Correspondence: Dr C Benjamin, Health Research Methodology and Implementation Hub (HeRMI), School of Health, University of Central Lancashire (UCLan), Room 434, Brook Building, Preston, Lancashire, PR1 2HE, UK. Tel: +44 01772 895403; Fax: +44 0177289 4968; E-mail: cbenjamin1@uclan.ac.uk

Received 7 October 2014; revised 2 January 2015; accepted 20 January 2015; published online 11 March 2015 
countries. Therefore, one aim of this research was to investigate the proportion of patients allocated to each discipline and provide evidence of multi-disciplinary working practices. Optimisation of workforce skill mix could increase the capacity of genetic services, enabling improved access for patients.

Currently, the utilisation of non-medical genetic counsellors varies across Europe and many countries only have a small number of practitioners. ${ }^{11}$ To safeguard the public and standardise practice, the European Board of Medical Genetics has defined a code of practice and registration system for genetic counsellors across Europe. ${ }^{12}$ English regional genetic services receive centralised funding. ${ }^{13}$ The services are provided free to patients at the point of access. The NHS England Medical Genetics Clinical Reference Group has responsibility for defining English service specifications and outcomes for the 23 regional genetics services. ${ }^{14}$ UK genetic counsellor professional registration is regulated by the UK and Eire Genetic Counsellor Registration Board. It is based on the principle that in addition to prior academic and vocational qualifications, registered genetic counsellors are required to have a 2-year training period and a Masters level portfolio assessment to become appropriately competent. ${ }^{15}$ In 2011, there were 272 genetic counsellor positions in the United Kingdom, but not all practitioners were registered with the GCRB. ${ }^{16}$ The current number of practitioners is unknown but 186 are UK Genetic Counsellor Board Registered. The majority work as part of a multi-disciplinary team attached to regional genetics services. ${ }^{17}$

The situation across Europe is complicated by differing economic policy, health-care professional roles, cultural preferences and political systems. Patient surveys show that there is great variability in access to genetic health care for diagnosis and on-going treatment. ${ }^{18,19}$ To meet this demand, clinicians are moving away from established models of service delivery and are developing innovative ways of working such as the integration of genetic and genomic testing within mainstream clinical specialty areas. ${ }^{20}$ This refinement of skill mix and workforce optimisation has been seen within other areas of health care typified by rising consumer demand and limited resources. ${ }^{21-23}$ Historically, the UK non-medical genetic service workforce provided psychosocial support and counselling that originated in many services from a community family nursing perspective. This aimed to provide ongoing holistic care to families affected by genetic conditions. This focus on continuity of care in a community setting has meant that some services still retain the option of offering a HV in certain circumstances if indicated by local protocols. This study was designed to describe practice within a regional genetics service and aimed to:

- Determine the proportion of patients allocated to clinical geneticist or genetic counsellor led care.

- Assess the usefulness of ICCG to aid allocation of telephone, clinic or HV for the initial contact.

- Describe the range of clinical contacts within a regional genetics service.

- Explore whether a genetic patient reported outcome measures questionnaire $^{24}$ and a patient satisfaction questionnaire ${ }^{25}$ can be incorporated into service provision.

\section{MATERIALS AND METHODS}

This observational prospective cohort study was undertaken in a UK regional genetics service serving a population of 2.7 million, with 3.9 full-time equivalent consultant clinical geneticists, 9.3 full-time equivalent genetic counsellors and 1 full-time equivalent genetic research nurse. This regional genetics service works closely with a local network of nurse-led breast cancer family history clinics, which provide genetic counselling for patients at low or moderate familial breast cancer risk. The service hosts a genetics practice development unit promoting collaborative working between medical staff, genetic counsellors, administrators and management. ${ }^{26}$ The study describes the usual care pathways (apart from the administration of the evaluation questionnaires) present in this service at the time.

Autonomous practice is defined in this study as 'a genetic counsellor working as part of a multi-disciplinary team, seeing patients independently and taking personal accountability for their actions'. The study was approved as a service evaluation by the hospital Research and Development Office.

\section{Participants}

The study included new patients referred to the service between 12 December 2011 and 12 March 2012. This period was chosen pragmatically due to funding constraints. A consecutive series of 650 new patient referrals (ie, 650 patients) were followed up until discharge (end of care episode) or until the 12th March 2013. If the referral was for a child, then this counted as one patient for this study. One or both parents were usually seen by the clinical team at the same time as the child.

\section{Referral management and triage process}

A study tracking sheet was attached to each patient file throughout their episode of care and staff entered the date and outcome for each contact. Data from this sheet was entered by the study administrator into a study database and this was used to prompt the administration of the patient reported outcome measure ${ }^{24}$ and patient satisfaction questionnaires. ${ }^{25}$ Data validation was undertaken by cross checking the study database information with patient notes and with the hospital patient information system. Outcomes included: patient group (paediatric, prenatal, adult non-cancer and adult cancer), allocation of health professional case lead, triage allocation, type of initial clinical contact offered where formal appointments were made between the hospital administration and the patient (telephone, face-to-face (F2F) in clinic or HV) and number of contacts per episode of care.

The referral letter was reviewed by a two person on-call team consisting of a clinical geneticist and a genetic counsellor who independently completed a referral management form (Supplementary material 1). The decision making process included whether to accept or decline the referral. Decline options included: decline with reasons; write back for more information or send the referral letter to another health-care service provider. Accepted referrals were allocated by the above on-call team to either genetic counsellor or consultant geneticist led care. Any discrepancies in allocations were discussed enabling both professional viewpoints to be expressed.

The genetic counsellor then allocated an initial clinical contact to be a telephone clinic (TC), F2F appointment in a clinic setting or HV according to a set of existing ICCG. These guidelines were developed before the study by the genetic counsellor clinical team and considered the psychological, medical and social factors supplied in the referral letter. The referral was allocated to one of 20 triage allocation categories which then determined the type of initial clinical contact offered to the patient (Supplementary material 2). The patient was sent a letter and a brochure explaining genetic counselling to inform their decision whether or not to opt into the service. This is standard practice in the service (Supplementary material 3 and 4 ).

\section{Patient questionnaires}

The study aimed to determine whether two self-reported questionnaires could be integrated into routine care and be used to evaluate the service. The Genetic Counselling Outcomes Scale-24 (GCOS-24) was developed for use as a patient reported outcome measure (PROM) within clinical genetics services and has been shown to be valid, reliable and sensitive to change. The GCOS-24 score measures change in emotional, cognitive, decisional and behavioural control, as well as emotional regulation and hope. ${ }^{24}$ The Zellerino seven item questionnaire was used to assess patient satisfaction after using clinical genetic services; this has been shown to have face validity and good internal consistency. ${ }^{25}$ The GCOS-24 was mailed to patients before and after clinical contact. The satisfaction questionnaire was mailed after each contact. No questionnaire reminders were sent. 
650 patient referrals $=825$ offered contacts

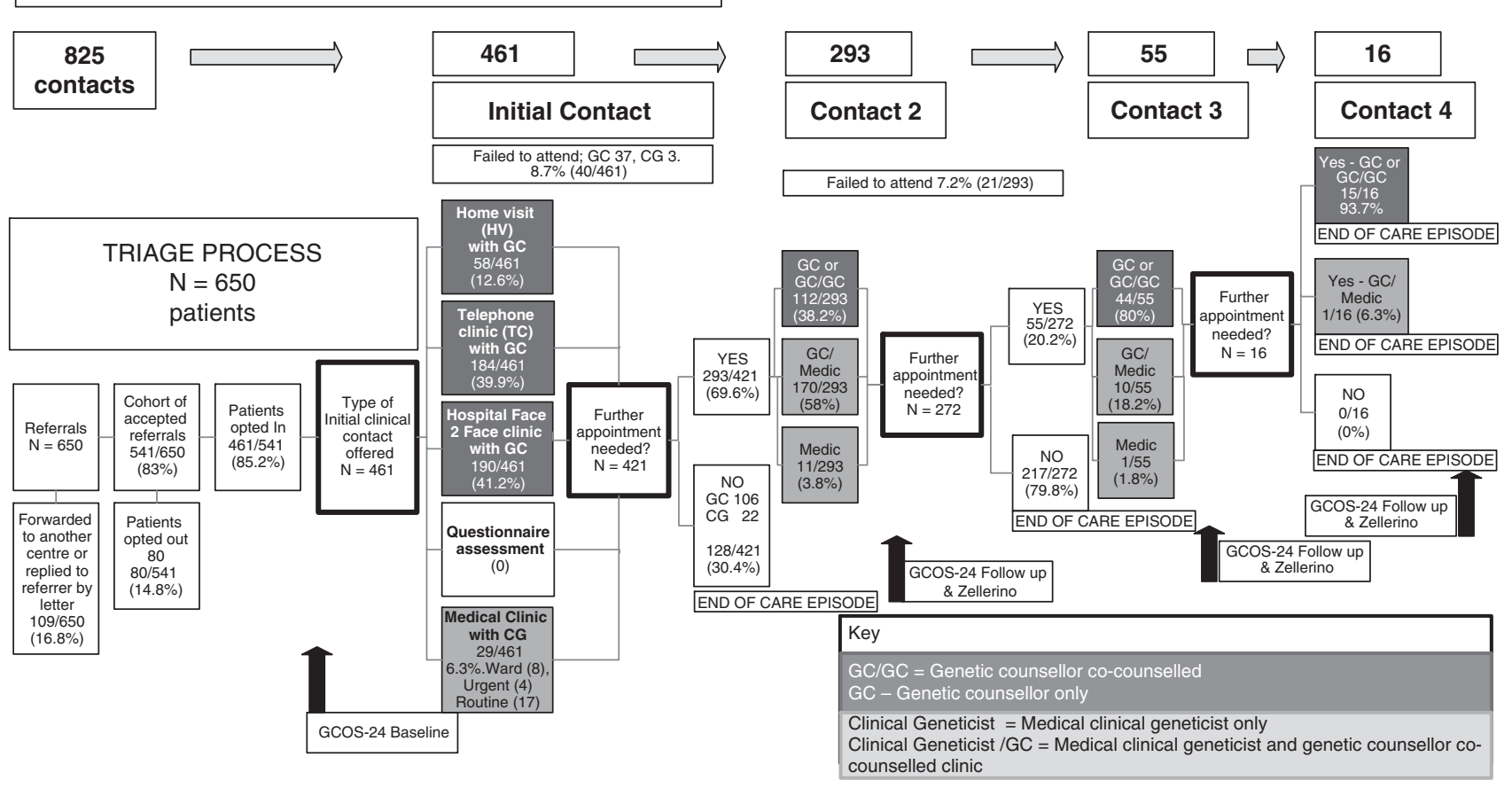

Figure 1 Progress of the 650 new patients referred over the 3-month period (12.12.2011-12.03.2012), resulting in 825 offered contacts - with 12 months of follow-up until 12.03.2013.

\section{RESULTS}

Referral management and triage

Figure 1 shows the patient pathways followed by 650 new patients. One hundred and nine referrals $(109 / 650,16.8 \%)$ did not meet the referral guidelines for the service and a letter was sent back to the referrer. In some of these cases alternative service providers were suggested such as nurse-led breast cancer family history clinics. All of the remaining 541 patients were sent a letter asking them to contact the hospital administration to schedule an initial clinical contact. Eighty $(14.8 \%)$ chose not to contact the service to make an appointment. This left 461 patients who were accepted by the service and who decided to opt-in, to whom 825 clinical contacts were offered $7.4 \%(61 / 825)$ of which were not attended. Types of patients included $36.3 \%$ paediatric $(236 / 650), 4.5 \%$ prenatal $(29 / 650), 23.8 \%$ adult non-cancer (155/650) and $35.4 \%$ adult cancer (230/650).

\section{Lead health professional}

Approximately half the patients, $46.2 \%$ (213/461) were triaged to genetic counsellor professional lead, with 53.8\% (248/461) being led by a clinical geneticist. The health professional lead was only changed in a few cases, with $44.3 \%(186 / 420)$ of patients receiving care led by genetic counsellors and $55.7 \%(234 / 420)$ led by clinical geneticists. The majority of patients $(432 / 461,93.7 \%)$, including those triaged to clinical geneticist lead, were offered an initial contact by a genetic counsellor. For $26.8 \%(106 / 395)$ of the patients who attended this was their only contact with the service, with the genetic counsellor able to complete the episode of care and discharge the patient. Genetic counsellors contributed to $95 \%$ (784/825) of the total contacts; clinical geneticists contributed to $26.9 \%$ (222/825). Five percent $(41 / 825)$ of contacts were with a clinical geneticist working alone in clinic compared with $65.7 \%(542 / 825)$ for genetic counsellors working alone in clinic.

Table 1 shows the decision outcome for triage allocation to lead professional and type of initial clinical contact offered according to the patient categories included within the ICCG. The categories which were more often $(P<0.005)$ triaged to clinical geneticist lead included; 'where a member of the patient's family had previously been seen and information known' (GC: 5/25 20\%, CG: 20/25 80\%), 'paediatric patients with and without developmental delay' (GC: 5/35 14.3\%, CG: 30/35 85.7\%), 'out-reach clinics' (GC: 5/20 25\%, CG:15/20 75\%) and 'where there was a new significant diagnosis in the family' (GC: $2 / 22$ 9.1\%, CG: $20 / 22$ 90.9\%). Those more often $(P<0.001)$ triaged to genetic counsellor lead included 'inherited cardiac diseases' GC: 29/34 85.3\%, CG: 5/34 14.7\%), 'cancer predictive testing' (GC: 30/40 75\%, CG: $10 / 4025 \%$ ) and 'any adult referral which did not fall into another category’ (GC: 87/126 69\%, CG:39/126 31\%).

\section{Range and type of clinical contacts}

Table 1 shows that the initial contact type offered matched well with those dictated by the ICCG (Figure 1). For 426 of the 461 (for whom triage allocation patient category and initial contact details were available), $39.9 \%$ were offered a TC with a genetic counsellor, $42 \%$ a hospital F2F clinic with a genetic counsellor, $13.2 \%$ a HV with a genetic counsellor and $4.9 \%$ a medical clinic with a clinical geneticist.

Table 2 shows the proportion of co-counselling, where either two genetic counsellors or a genetic counsellor and a clinical geneticist were present with both contributing to the counselling process for the duration of the patient consultation. The overall rate of co-counselling in this study was $29.3 \%(242 / 825)$, with the genetic counsellor and clinical geneticist co-counselling in $21.9 \%$ and two genetic counsellors 


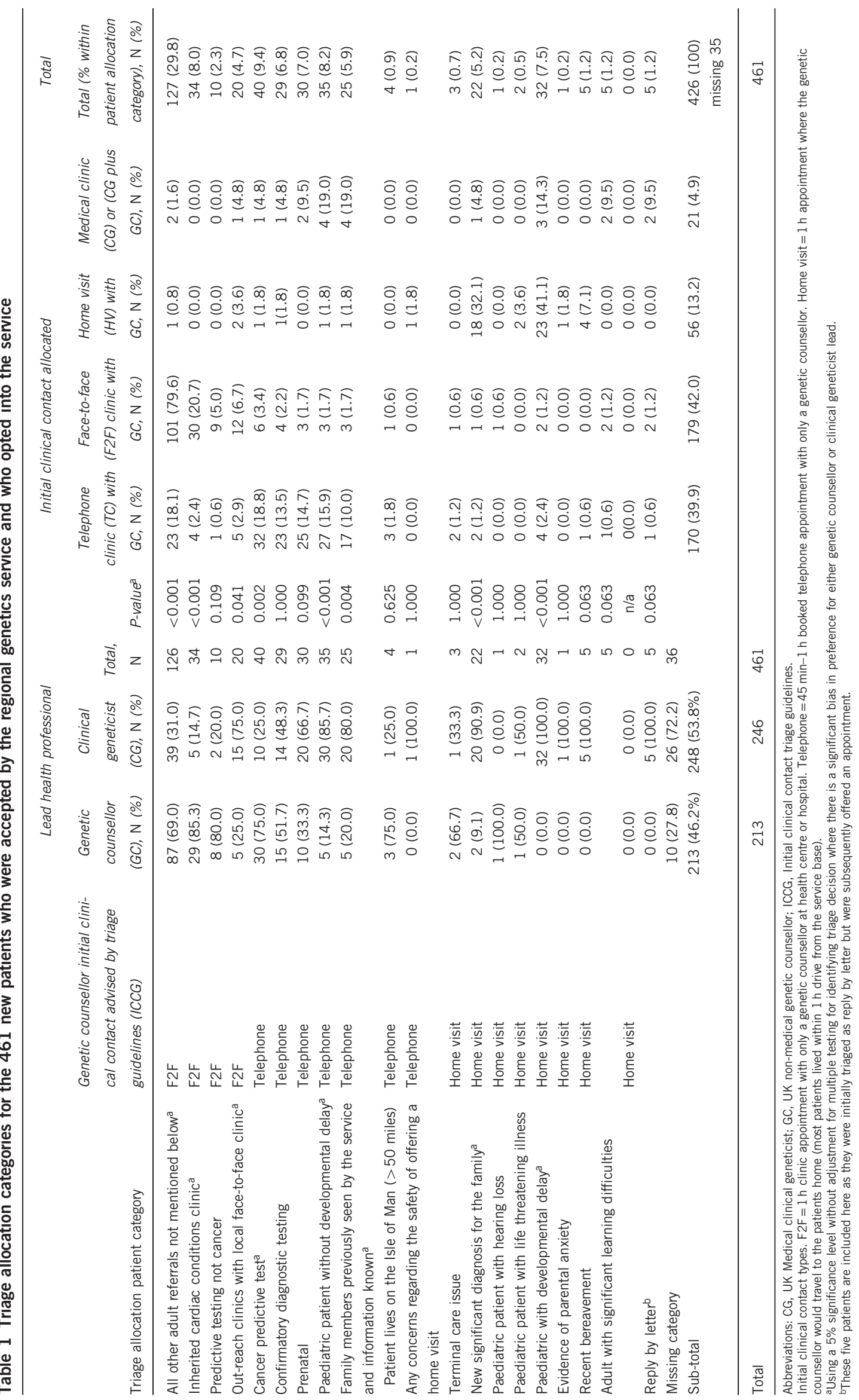


co-counselling in $7.4 \%$ of consultations. The latter mainly represents genetic counsellor-led predictive testing for cancer, Huntington disease and cardiac conditions. Overall, 86\% (345/400) of patients who attended their appointments completed their episode of care and were discharged after one or two appointments. Only 6.7\% (55/825) and $1.9 \%(16 / 825)$ of total contacts received third and fourth appointments.

\section{Patient questionnaires}

Developing a robust process that allowed integration of evaluation questionnaires into routine service delivery proved problematic. This stemmed from problems with patient identification at baseline and the end of care. Only 388 out of a possible 850 satisfaction questionnaires were sent out. Ninety-seven were received (response rate 25\%). This selected group of patients were satisfied by the care received by their health professional with greater than $80 \%$ stating that they 'agree somewhat' or 'strongly agree' to six out of seven questions covering; information provided, time spent, ability to answer questions, listening and engaging the patient as a partner in planning care (Figure 2).

Implementation of the questionnaires in a clinical setting was challenging. Issues identified included; a centralised clinic administration system shared with other departments and that no additional resources were available to compensate for administration time spent identifying study cohort patients during the follow-up period. Difficulties tracking follow-up patients with the hospital patient management system meant that a reliable estimate of questionnaires sent and response rate was not possible. Only 38 pre- and post-genetic counselling GCOS-24 questionnaires were available for analysis. Those analysed showed a statistically significant difference between baseline and follow-up score (mean baseline score $=106.5$, mean post-care episode score $116.1, P=0.007 \mathrm{df} 37$ ), indicating that this sub-set of patients reported significant benefits from their contact with the genetics service. $^{27}$

\section{DISCUSSION}

The proportion of patients allocated to clinical geneticist or genetic counsellor care

The genetic counsellors in this study led patient care for a range of genetic conditions. However, they did not take the lead for paediatric patients with developmental delay or patients with new significant diagnoses. The service did not have a 'specific' list of genetic diagnoses that were suitable for genetic counsellor led care; often this allocation was dependent on the specific information provided in the individual patient referral letter. The decision making process seemed to be driven by whether there was evidence of diagnostic uncertainty or a complex medical phenotype (allocation to clinical geneticist lead) or a known diagnosis or psychological or social issues in a family (allocation to genetic counsellor lead). This supports evidence from Skirton et al's systematic review of current non-medical genetic counsellor practice. ${ }^{10}$ This found that the majority of genetic counsellors working in other countries did not autonomously counsel cases where the diagnosis was uncertain or there was a need for a clinical examination. ${ }^{10}$

The genetic counsellors in this study provided $73 \%$ (603/825) of the total offered contacts, as either genetic counsellor only contacts or genetic counsellor co-counselled contacts. Genetic counsellors led care for $44.3 \%(186 / 420)$ of the patients. There is similar evidence from the United States where one study reports the motivation to initiate an

Table 2 Number of patient contacts offered to the 461 patients opting into the service

\begin{tabular}{|c|c|c|c|c|c|}
\hline \multirow[b]{2}{*}{ Health professionals present } & \multicolumn{4}{|c|}{ Number of patient contacts offered to the 461 patients } & \multirow[b]{2}{*}{ Total } \\
\hline & Initial contact & Contact 2 & Contact 3 & Contact 4 & \\
\hline Genetic counsellor only & $432(93.7 \%)$ & $74(25.3 \%)$ & $25(45.4 \%)$ & $11(68.8 \%)$ & $542(65.7 \%)$ \\
\hline Genetic counsellor/genetic counsellor co-counselled & $0(0.0 \%)$ & $38(13.0 \%)$ & $19(34.6 \%)$ & $4(25.0 \%)$ & $61(7.4 \%)$ \\
\hline Clinical geneticist/genetic counsellor co-counselled & $0(0.0 \%)$ & $170(58.0 \%)$ & $10(18.2 \%)$ & $1(6.2 \%)$ & $181(21.9 \%)$ \\
\hline Clinical geneticist only & $29(6.3 \%)$ & $11(3.7 \%)$ & $1(1.8 \%)$ & $0(0.0 \%)$ & $41(5.0 \%)$ \\
\hline Total & $461(55.9 \%)$ & $293(35.5 \%)$ & $55(6.7 \%)$ & $16(1.9 \%)$ & $825(100.0 \%)$ \\
\hline
\end{tabular}

Q2:My provider explained things in a way that was easy to understand.

Q3:I received the information I needed from my provider Q4:My provider helped me feel like a partner in care. Q5:My provider spent enough time with me.

Q6:I was able to share all the necessary information with my provider. Q7:My provider answered all my questions.

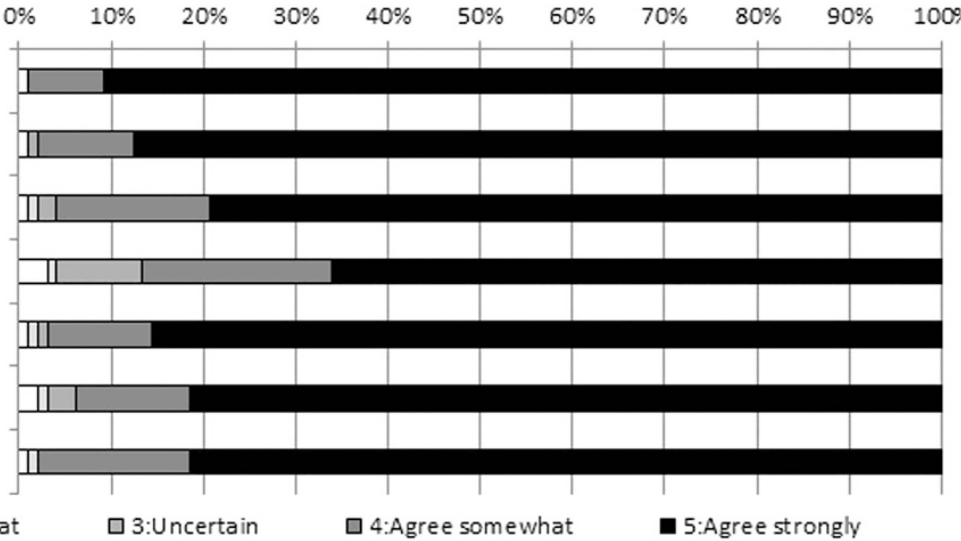

Figure 2 Patient satisfaction with the genetics service as measured by the Zellerino satisfaction questionnaire (97/388). 
independent genetic counsellor clinic was to relieve the pressure on the clinical geneticist's clinic. ${ }^{28}$ In that study, $80 \%$ of a pre-selected group of 321 patients seen did not need an additional appointment with a geneticist. In Australia, a descriptive retrospective analysis of 4817 cases saw that $42 \%$ of sessions in one region were conducted by the genetic counsellor alone. ${ }^{29}$ In South Africa, genetic counsellors independently saw $39 \%$ of the 3365 referred patients covering 57 different diagnoses. ${ }^{30}$ The current study did not explore the health professional allocation decision making process in-depth and this is a potential area for further research.

\section{The range of clinical contacts}

In only 5\% (41/825) of contacts did medical clinical geneticists provide counselling alone in clinic. However, they usually led the $21.9 \%$ (181/825) co-counselling contacts with a genetic counsellor colleague. In this service, the $53.8 \%(248 / 461)$ of the patients who required a clinical geneticist led consultation would have usually been seen independently by a genetic counsellor before scheduling a second clinical contact as a clinical geneticist/genetic counsellor co-counselling contact. The rates of clinical geneticist and genetic counsellor cocounselling contacts in this regional genetics service were higher than the English average at $21.9 \%(181 / 825)$ vs $9.9 \%$ recorded for the cocounselled rate of patients by the NHS Medical Genetics English Winter (Q3) 2013 Dashboard National Average Figures (personal communication Chair Medical Genetics Clinical Reference Group). There is currently variation in the rate of patient co-counselling between different genetic services in England, the range for this indicator being between 0 and $74.9 \%$, with the majority of centres reporting within the $1-9 \%$ range. Possible reasons for such a high rate of clinical geneticist/genetic counsellor co-counselling contacts in this service included the teams focus on providing a continuum of care for the patient aiming to maintain contact with the same genetic counsellor before, during and post clinic contacts.

Co-counselling has been one of many historical service delivery models in the United Kingdom. Co-counselling provides a multidisciplinary approach to the holistic care of the patient and the opportunity for counsellors to focus and address different clinical and psychosocial aspects within the same consultation. Co-counselling also has benefits for the workforce as a learning opportunity for junior staff or staff expanding their scope of practice to include new areas of practice and updating. However, there are disadvantages of cocounselling, such as the increased expense of two health professionals being present and complexities in scheduling appointments.

Genetic counsellor only contacts were higher in this study at $73.1 \%$ than the English average of $44.6 \%$ rate of patient appointments performed by a genetic counsellor only. At the time of this study, the service had one of the lowest proportions of medical clinical geneticists per population covered compared with the other 19 English RGS. This required the development of effective time management and support from medical clinical geneticists for joint case review enabling genetic counsellors in this service to independently counsel for a wide range of conditions (eg, high-risk cancers, cardiac conditions and Huntington disease).

In this study, $29.1 \%(189 / 650)$ of referrals were not offered a clinical contact, representing indirect patient care which is not directly obvious from clinic attendance figures and could be overlooked when assessing workload. Of these, 94 were not accepted into the service based on the English national service specification of appropriate referrals. ${ }^{13}$ Many of these were patients deemed to be at moderate risk of cancer which were re-directed to a network of nurse-led family history screening clinics based within oncology services. Patients re-directed to these services saw a 'specialism-specific genetic nurse' (SSGN), a registered nurse working at a specialist level of practice in a clinical specialism but with additional genetics training. A UK evaluation has shown these roles to be acceptable to patients and effective in terms of improving patient access to genetic information and tests. ${ }^{31-33}$

This study is novel as it provides the first empirical evidence of the contribution of genetic counsellors within a UK regional genetic service multi-disciplinary team. Study limitations include that it describes the experience of a cohort of incoming referrals for a period of only 3 months in one centre. The practice of this one service may not be representative of other services across the United Kingdom.

\section{Use of ICCG}

The anticipated reduction in the proportion of HVs from $26 \%$ in $2010 / 2011$ to the $13 \%$ seen in this study $(2011 / 2012)$ is thought to be a consequence of implementing revised ICCG. The revised guidelines allowed for HVs to be standardised across the team and provided appropriately. The study demonstrated that it was possible using the guidelines to allocate patients into differing initial contact types based on the requirements of the specific case. However, this individualised process was difficult to merge with inflexible clinic booking systems and resulted in many separate clinic queues, increasing waiting times due to patients waiting for an initial TC 'slot' when other 'appointment slots' were free in other hospital clinics. Of concern were the $21.9 \%$ (181/825) of contacts which were cocounselled by both a genetic counsellor and a clinical geneticist, due to the time commitment required by both health professionals.

\section{Moving forwards}

A decision was made to plan a service re-design to move towards a 'one clinic fits all' system. In this model, genetic counsellors and clinical geneticists have separate clinics, booking is on a first come, first served basis, irrespective of the clinical condition (although adhering to triage health professional appropriate lead) or whether it is an initial or subsequent contact. The clinician still reserves the ability to perform a telephone counselling session within the allocated clinic slot if that would best meet the needs of the patient. For some patients, a telephone contact to discuss concerns and facilitate a confirmation of diagnoses is thought to be most efficient. If the referral letter raises any specific psychosocial concerns, then the genetic counsellor can still ask for a co-counselling consultation to occur (including for predictive testing) or a HV.

There is on-going debate as to how to most efficiently gather family history information; an initial genetic counsellor consultation usually consists of many other elements than purely information gathering. In some services, the information gathering is done by specially trained administrative staff - releasing genetic counsellor time to focus on psychosocial and educative issues. One requirement of the 'one clinic fits all' model is that the most appropriate health professional with the required skills sees the patient. It is not always possible or suitable that each health professional is able to provide counselling for all genetic conditions and often facilities are not available to provide an appropriate clinical environment for pre-natal, paediatric and adult patients. This design relies on a workforce that has access to and time for continuing professional development as well as dedicated clinic facilities.

A framework for implementation of genetic services has recently been proposed by Rigter $e t a^{34}$ to provide structure for the transition process towards new ways of working. They defined three influencing factors: different ways of doing, different ways of thinking and 
different ways of organising. The authors proposed a process of deepening, broadening and scaling up of any new service. This framework could be used to help implement future service re-design.

There remains the need to evaluate the effectiveness of new service designs and how the limited workforce of clinical geneticists and genetic counsellors can be utilised to increase access to genetic services and provide safe patient care. Currently, many European countries have limited or no non-medical genetic counsellors, although with increased demand for access to specialist knowledge the cost effectiveness of genetic counsellors over clinical geneticists may become attractive. This study has demonstrated that appropriately trained and resourced genetic counsellors engaging in multidisciplinary working practice can provide a significant proportion of patient contacts. Studies undertaken in other areas of health care could inform the optimum use of skill mix and multi-disciplinary practice. The development of the specialism specific genetic nurse (SSGN) role within mainstream clinical specialty areas such as oncology, cardiology or endocrinology adds another route through which patients could access genetic services. Cohen et $a l^{35}$ call for a shared terminology when describing genetic service delivery models. However, comparison of service delivery models between and within countries remains difficult due to the influence of social, political and historical factors. ${ }^{36,37}$ In the United States a recent survey shows wide variation in genetic counsellor service delivery models, unfortunately in part this variation is explained by limits imposed by billing and bureaucracy, not always by good practice. ${ }^{38}$

The methodological techniques of implementation science, ${ }^{39}$ including the conduct of implementation trials and the study of complex interventions could be beneficial in building the evidence base on which to develop new ways of working to optimise skill mix and workforce utilisation in genetic service delivery models. ${ }^{40}$ Further research needs to be undertaken to establish how best to integrate patient reported outcome and satisfaction measures within routine genetic health service delivery.

\section{CONFLICT OF INTEREST}

The authors declare no conflict of interest.

\section{ACKNOWLEDGEMENTS}

We would like to thank the patients and staff of Liverpool Women's Hospital NHS Foundation Trust and acknowledge the funding from a Charitable Trust Grant, Liverpool Women's Foundation (NHS) Hospital Trust. We would also like to thank Dr Lois Thomas, Reader in Health Services Research, UCLan (University of Central Lancashire) for her helpful suggestions on earlier drafts of this paper.

1 Evans D, Barwell J, Eccles D et al: The Angelina Jolie effect: how high celebrity profile can have a major impact on provision of cancer related services. Breast Cancer Res 2014; 16: 442

2 Goldsmith L, Jackson L, O'Connor A, Skirton H: Direct-to-consumer genomic testing from the perspective of the health professional: a systematic review of the literature. J Commun Genet 2013; 4: 169-180.

3 Schwartz MD, Valdimarsdottir HB, Peshkin BN et al: Randomized noninferiority trial of telephone versus in-person genetic counseling for hereditary breast and ovarian cancer. J Clin Oncol 2014; 32: 618-626.

4 Iredale R, Jones L, Gray J, Deaville J: 'The edge effect': an exploratory study of some factors affecting referrals to cancer genetic services in rural Wales. Health Place 2005 11: 197-204

5 McCann E, Baines EA, Gray JR, Proctor AM: Improving service delivery by evaluation of the referral pattern and capacity in a clinical genetics setting. Am J Med Genet C Semin Med Genet 2009; 151C: 200-206.

6 Delikurt T, Williamson G, Anastasiadou V, Skirton H: A systematic review of factors that act as barriers to patient referral to genetic services. Eur J Hum Genet 2015; 23: 739-745
7 Benjamin C Cochrane (EPOC) Title Registration. Interventions to improve patient access, service utilization and cost of providing genetic counselling services http:// summaries.cochrane.org/title/interventions-to-improve-patient-access-service-utilizationand-cost-of-providing-genetic-counselling-services (accessed December 2014).

8 Miller-Keane: Definition of Healthcare Teams. 7th edn. http://medical-dictionary. thefreedictionary.com/team Elsevier, 2003. (accessed December 2014).

9 Kerr B, Turnpenny P Bromillow G on behalf of the Association of Genetic Nurses and Counsellors and Clinical Genetics Society: Professional Roles in the Multidisciplinary Team in Clinical Genetics. A Framework for Practice prepared by a Working Party of the Association of Genetic Nurses and Counsellors and Clinical Genetics Society http://www. clingensoc.org/media/43550/wp_agnc_cgs_v2.pdf (accessed December 2014) 2011.

10 Skirton $\mathrm{H}$, Cordier $\mathrm{C}$, Ingvoldstadt $\mathrm{C}$, Taris N, Benjamin CM: The role of the genetic counsellor: a systematic review of research evidence. Eur J Hum Genet 2015; 23. $452-458$.

11 Cordier C, Lambert D, Voelckel MA, Hosterey-Ugander U, Skirton H: A profile of the genetic counsellor and genetic nurse profession in European countries. J Commun Genet 2012; 3: 19-24.

12 Skirton H, Cordier C, Lambert D, Hosterey Ugander U, Voelckel MA, O'Connor A: A study of the practice of individual genetic counsellors and genetic nurses in Europe. J Commun Genet 2013; 4: 69-75.

13 England NHS Specialised Services National Definitions Set - Medical Genetics E01/S/a http://www.england.nhs.uk/wp-content/uploads/2013/06/e01-med-gen. pdf 2013 (accessed December 2014).

14 NHS England Clinical Reference Group Medical Genetics: Outline Specification for the Specialist Commissioning of Genetic and Genomic Services for England. 2014; http://www.bsgm.org.uk/media/883258/bshg_july_51.pdf pp 22-25 (accessed December 2014)

15 Barnes C, Kerzin-Storrar L, Skirton H, Tocher J: The Department of Health-supported genetic counsellor training post scheme in England: a unique initiative? J Commun Genet 2012; 3: 297-302.

16 Personal Communication. Association of Genetic Nurses and Counsellors: Results from joint AGNC/lead genetic counsellor meeting 20 October 2011. Available from the Chair of the Association of Genetic Nurses and Counsellors.

17 Skirton $\mathrm{H}$, Kerzin-Storrar L, Barnes $\mathrm{C}$ et al: Building the genetic counsellor profession in the United Kingdom: two decades of growth and development. J Genet Couns 2013; 22: 902-906

18 EURORDIS Rare Diseases Europe, Kole A, Faurisson F The voice of 12,000 patients. Experiences and Expectations of Rare Disease Patients on Diagnosis and Care in Europe. A report based on the EurordisCare2 and EurordisCare3 Surveys 2009, http:/ www.eurordis.org/publication/voice-12000-patients (accessed December 2014).

19 Rare Disease UK: Experiences of Rare Diseases: An insight from Patients and Families http://www.raredisease.org.uk/documents/RDUK-Family-Report.pdf 2010 (Accessed December 2014)

20 Burton H, Cole T, Farndon P: Genomics in Medicine - Delivering Genomics Through Clinical Practice. Public Health Genetics Foundation, 2012.

21 Laurant M, Reeves D, Hermens R, Braspenning J, Grol R, Sibbald B: Substitution of doctors by nurses in primary care. Cochrane Database Syst Rev 2005; (2): CD001271.

22 Richardson G: Identifying, evaluating and implementing cost-effective skill mix. J Nurs Manag 1999; 7: 265-270.

23 Dierick-van Daele ATM, Spreeuwenberg C, Metsemakers JFM, Vrijhoef BJM: Critical appraisal of the literature on economic evaluations of substitution of skills between professionals: a systematic literature review. J Eval Clin Pract 2008; 14: 481-492.

24 McAllister M, Wood A, Dunn G, Shiloh S, Todd C: The Genetic Counselling Outcome Scale: a new patient reported outcome measure for clinical genetics services. Clin Genet 2011; 79: 413-424.

25 Zellerino B, Milligan SA, Brooks R, Freedenberg DL, Collingridge DS, Williams MS Development, testing, and validation of a patient satisfaction questionnaire for use in the clinical genetics setting. Am J Med Genet C Semin Med Genet 2009; 151C 191-199.

26 Norris A: Practice development unit - every person makes a difference. BMJ Support Palliat Care 2011; 1: 258-259.

27 McAllister M, Payne K, Nicholls S, MacLeod R, Donnai D, Davies L: Patient empowerment in clinical genetics services. J Health Psychol 2008; 13: 887-897.

28 Hannig V, Cohen M, Pfotenhauer J, Williams M, Morgan T, Phillips JR: Expansion of genetic services utilizing a general genetic counseling clinic. J Genet Couns 2013; 23: $64-71$

29 Kromberg JGR, Parkes J, Taylor S: Genetic counselling as a developing healthcare profession: a case study in the queensland context. Aust J Prim Health 2006; 12: 33-39.

30 Kromberg JGR, Wessels T-M, Krause A: Roles of genetic counsellors in South Africa J Genet Couns 2013; 6: 753-761.

31 Kirk M, Simpson A, Llewellyn M, Tonkin E, Cohen D, Longley M: Evaluating the role of Cardiac Genetics Nurses in inherited cardiac conditions services using a Maturity Matrix. Eur J Cardiovasc Nurs 2014; 13: 418-428.

32 Martin G, Weaver S, Currie G, McDonald R, Finn R: Innovation sustainability in challenging health-care contexts: embedding clinically led change in routine practice. Health Serv Manage Res 2012; 25: 190-199.

33 Bennett CL, Burke SE, Burton H, Farndon PA: A toolkit for incorporating genetics into mainstream medical services: Learning from service development pilots in England. BMC Health Serv Res 2010; 10: 125.

34 Rigter T, Henneman L, Broerse J, Shepherd M, Blanco I, Kristoffersson U et al: Developing a framework for implementation of genetic services: learning from examples 
of testing for monogenic forms of common diseases. J Commun Genet 2014; 5: 337-347.

35 Cohen SA, Marvin ML, Riley BD, Vig HS, Rousseau JA, Gustafson SL: Identification of genetic counseling service delivery models in practice: a report from the NSGC Service Delivery Model Task Force. J Genet Couns 2013; 22: 411-421.

36 Cohen S, Gustafson S, Marvin ML, Vig HS, Rousseau J A, Gustafson SL et al: Report from the National Society of Genetic Counselors service delivery model task force: a proposal to define models, components, and modes of referral. J Genet Couns 2012; 21: 645-651.
37 Battista RN, Blancquaert I, Laberge AM, van Schendel N, Leduc N: Genetics in health care: an overview of current and emerging models. Public Health Genomics 2012; 15: 34-45.

38 Trepanier A, Allain D: Models of Service delivery for cancer genetic risk assessment and counselling. J Genet Couns 2014; 23: 239-253.

39 Peters DH, Taghreed A, Alonge 0: Implementation research: what it is and how to do it. BMJ 2013; 347: 1-7.

40 Craig P, Dieppe P, Nacintyre S, Mitchie S, Nazareth I, Petticrew M: Developing and evaluating complex interventions: the new Medical Research Council guidance. BMJ 2008; 337: 979-983.

Supplementary Information accompanies this paper on European Journal of Human Genetics website (http://www.nature.com/ejhg) 